\title{
ALIGNMENT OF INTERNAL AND EXTERNAL BUSINESS AND INNOVATION DOMAINS
}

\author{
B.R. Katz ${ }^{1 *}$, N.D. du Preez ${ }^{1} \&$ L. Louw ${ }^{1}$
}

\section{ARTICLE INFO}

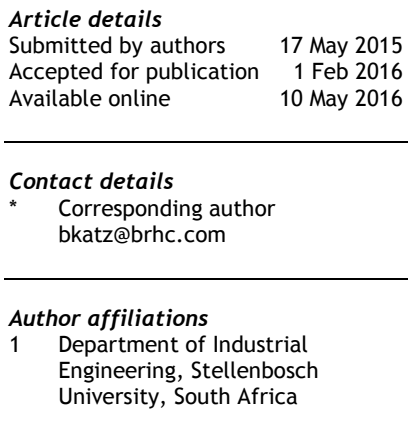

DOI

http: //dx.doi.org/10.7166/27-1-1247

\section{ABSTRACT}

"Instead of being really good at doing some particular thing, companies must be really good at learning how to do new things" [1]. This ability to do new things involves both the identification and the mastery of the next 'new thing' as well as the ability to align the rest of the company with this new direction. This paper focuses on the alignment of innovation activities with the overall business strategy and infrastructure. An innovation strategic alignment model is presented that supports alignment in a company by identifying the driver of change and its impact on other areas of the business.

\section{OPSOMMING}

\begin{abstract}
"Instead of being really good at doing some particular thing, companies must be really good at learning how to do new things" [1]. Die vermoë om iets nuut te doen berus op beide die identifisering en bemeestering van die nuutheid, sowel as die belyning van die bestaande maatskappy met hierdie nuwe wending. Hierdie artikel belig die belyning van innovasie aktiwiteite binne die onderneming met die algemene besigheidstrategie asook infrastruktuur. 'n Innovasiestrategie belyningsmodel word voorgestel. Hierdie model ondersteun belyning deur identifisering van die drywer van verandering en die impak daarvan op ander besigheidsareas.
\end{abstract}

Different improvement initiatives within a company happen for different strategic, technical, and operational reasons, and are executed by different teams. Alignment of these initiatives has been shown to be a key competency required by companies to implement strategy successfully and achieve strategic goals and objectives [2,3]. As well as aligning operational business units with business strategy, aligning certain support functions, such as HR and IT, has been widely researched and documented $[4,2,5,6]$.

This paper focuses on the alignment of a company's innovation activities with the overall company strategy and structure. The paper starts by describing the relationship between change and alignment, and how the ability to align a company after a change is a vital competitive advantage. It describes different types of alignment models. One such model is the strategic alignment model (SAM). It was originally developed to provide a framework to align IT strategy and infrastructure with business strategy and infrastructure, to raise the IT function in a company from its traditional orientation of administrative support to a strategic role [4].

In this paper, the SAM is adapted to develop a model combining innovation with strategic and structural alignment. This model is termed the 'innovation strategic alignment model' (iSAM). Its purpose is to define and connect the different components, tools, and methods required to align internal and external innovation domains and a company's overall business strategy and structure. This is achieved by integrating a range of innovation components, including innovation scope, 
governance, capability, models, processes, and skills; and by aligning these with the overall business strategy and structure.

With iSAM thus defined, the paper explains how a practical approach using iSAM can be roadmapped to enable a company to assess its current innovation alignment and make adjustments to the four domains in iSAM to improve alignment. The paper concludes with the application of iSAM in a mid-size consulting company. In this case study, the innovation alignment of the company is assessed, and conclusions are drawn about the appropriateness of the current innovation alignment.

\section{ALIGNMENT AND CHANGE}

Traditional competitive advantages such as market position, scale, production capabilities, and delivery models are essentially static competencies in today's uncertain business environment [1]. These competencies, while still important in gaining competitive advantage, take a significant time to develop, and may quickly become irrelevant in a fast-changing world. "Instead of being really good at doing some particular thing, companies must be really good at learning how to do new things" [1]. 'New things' essentially require change. Different types of change can occur in a company. Change can be used to support the achievement of the business strategy, to do things better, or it can change the business strategy by doing things differently [7]. Change in a company ranges on a continuum from small optimisations of current activities to significantly radical and disruptive innovation [8]. Being good at change is not just about executing the specific change successfully; it is also about how the rest of the company is aligned with the change.

Alignment is defined as the "proper or desirable coordination or relation of components" [9]. In the context of strategy, alignment is described as the fit between a company's internal structure and its external environment [10]. Strategic alignment is also described as "that optimal state in which strategy, employees, customers and key processes work in concert to propel growth and profits" [11]. Kaplan and Norton extend these definitions to include the linking and coordination of various functional departmental strategies, and the support these strategies provide, to the overall business strategy [12]. Traditionally alignment has supported the implementation of a strategy. Once a new strategy is defined, the company has to be re-aligned in order to ensure that it can achieve the new strategic objectives. Alignment has been shown to be a key competency required by highly successful companies to implement their strategy successfully and achieve strategic goals and objectives [2,3]. In today's world, innovation and change can be initiated anywhere in a company, and those changes can have an impact on all parts of the business, including its strategic direction. Alignment, therefore, is also a key competency for the successful implementation of change in a company.

\section{ALIGNMENT MODELS}

A number of different types of alignment model are documented. The balanced scorecard model aligns the operations planning of a company with the support functions planning at an enterprise level down to a strategic business unit level. The balanced scorecard also uses the alignment of goals and objectives across different business units and at different levels in a company [13]. A conventional alignment model maps a company's mission, vision, and strategy to its people, systems, technology, and processes. Culture often falls into the people component of this type of alignment model. A similar model also includes alignment of customers [11]. Strategy alignment maturity models describe a number of levels of alignment maturity by which a company can measure its overall alignment maturity [14]. The strategic alignment model (SAM) focuses on the alignment between the business and its information technology strategy, infrastructure, and processes [4]. The SAM provides a comprehensive set of domains and components to align a function within a company to the company's strategy, infrastructure, and processes.

\subsection{The strategic alignment model (SAM)}

The strategic alignment model (SAM) of Henderson and Venkatraman [4] makes several critical assumptions about the relationship between the business and the information technology (IT) function. The first is that the inability of a company to realise value from its IT investment is due to the lack of alignment between this investment and the business strategy. The second assumption is that economic performance is directly related to a management team's ability to 
align the administrative structures of a company with the organisation's direction or strategy. This assumption is consistent with the generally accepted view that internal and external decisions need to be consistent with each other. Finally, Henderson and Venkatraman state that, due to the dynamic nature of technology and a competitive business environment, which may require an immediate response to a competitor's move, it is not sufficient for a business to be sophisticated in a specific technology. Sustainable competitive advantage also lies in a company's ability to adjust to new technologies and competitors' movements. This requires a company to be able to discover or adopt new technologies and master these technologies on a continual basis [4]. These three assumptions change the fundamental role of IT in a company from a supporting, back-office activity to one of strategic importance. The aim of the SAM is to present managers with a range of strategic choices to assist them in defining this alignment. The SAM recognises the need to take both internal and external domains into account when addressing strategic alignment. The logic, which states that the alignment between a company's external positioning and its internal organisation is critical for economic success, has been applied to IT alignment. Both internal and external IT domains are defined and linked to each other and to the internal and external business domains.

\section{THE INNOVATION STRATEGIC ALIGNMENT MODEL (ISAM)}

The concept of Henderson and Venkatraman's [4] strategic alignment model (SAM) is used to define an innovation strategic alignment model (iSAM). The three assumptions made by Henderson and Venkatraman in relation to business and IT strategic alignment are also applicable to business and innovation strategic alignment. From an innovation perspective the assumptions are:

1. The inability of a company to realise value from its innovation investment is due to the lack of alignment between this investment and the business strategy.

2. Innovation performance is directly related to a management team's ability to align the administrative innovation structures of a company with the organisation's innovation direction or strategy.

3. Sustainable competitive advantage lies in a company's ability to innovate continually and not just in a single innovation.

In relation to the first assumption: only as managers increasingly understand the relationship between strategy and innovation, and synergies between these two are achieved, will benefits from innovation become more likely [15]. In the 2010 CapGemini innovation leadership study, 46 per cent of the respondents considered the lack of a well-articulated innovation strategy, or the inability of the company to communicate this strategy, as the most significant reason for missing innovation targets [16]. Eighty per cent of respondents in the same Capgemini study whose company had an explicit innovation strategy said that the strategy contained a section on the alignment with the overall business strategy [16]. In a Booz\&co global innovation survey of the 1,000 public companies that spent the most on research and development, it was revealed that the companies with highly-aligned cultures and strategies outperform poorly-aligned companies in both profits and company value [17].

In relation to the second assumption: innovation surveys have continually shown that achieving positive results from innovation requires a long-term focus and the on-going commitment of a range of resources, including financial, technological, infrastructural, and people [15]. It also emphasised the importance of innovation governance [18].

In relation to the third assumption: Teece et al. [19] discuss the emerging dynamic capabilities paradigm, which emphasises the company's ability to adjust internal and external competences to address rapidly-changing environments. This approach is likely to show significant value in "regimes of rapid technological change" [19]. Dynamic capability seems to have a strong relationship with innovation capability, and a company's ability to adapt to changing conditions through innovation is a source of competitive advantage [8]. These three assumptions, from an IT perspective, elevate the fundamental role of IT to one of strategic importance. Similarly, companies have been challenged to move innovation from purely the research and development arena to become more pervasive and strategic within the business. 


\subsection{External domain components of iSAM}

The external domain, with regard to innovation, defines how a company is positioned in the innovation environment. Within the external domain of both the business strategy and the IT strategy in the SAM, three components are described. They represent three sets of choices that managers need to address. We postulate that three similar sets of parameters are required by managers in relation to innovation strategy. These are:

\subsubsection{Innovation scope}

Innovation scope determines how wide and deep the innovation focus will be within the company. This is analogous to business scope, which defines the choices related to depth and breadth of product-market offerings, and to IT scope, which defines the specific technologies that support current business strategies. There are many definitions of innovation scope and related metrics. These include:

- $\quad$ the number of innovations adopted in a given time period [20],

- $\quad$ incremental innovation or systemic innovation [21],

- different innovation types (product, process, administrative innovation) [22],

- creating narrow and specialised knowledge by focusing on depth of innovation vs creating broad technological knowledge by emphasising diversity of innovation [23], and

- a matrix including innovation level (incremental vs radical) on one axis and a range of innovation types on the other [24].

Within iSAM, innovation scope is defined as the combination of:

- $\quad$ innovation type (product, process, strategic),

- innovation level (radical, incremental), and

- innovation impact (sustaining, disruptive) [25].

\subsubsection{Innovation governance}

Innovation governance involves the choice of frameworks that define the mission, focus, and implementation of innovation in a company [18]. This is analogous to business governance, which is a set of principles, policies, and business rules that establishes how the business is run and that is monitored by governance forums such as an advisory board and an innovation director on the executive committee. An innovation governance framework supports a company in addressing questions of innovation content and innovation process. Six fundamental questions should be addressed by a comprehensive innovation governance system [18]. These are:

- Why do you want to innovate?

- Where do you look for innovation?

- How much innovation do you target?

- How can you innovate more effectively?

- With whom should you innovate?

- Who should be responsible for what in innovation?

\subsubsection{Innovation capability}

The ability of a company to innovate is based on a defined set of factors that can be used to determine a company's innovation capability [8]. Companies can choose which factors to develop in order to secure competitive advantage. This is analogous to business distinctive competencies, which deal with attributes of strategy such as pricing, quality, value-adding services, and unique distribution channels. These are competencies of a business that distinguish it from its competition. Innovation capability is "the organisational means with which innovative outputs may be facilitated" [8]. It is also described as the potential of an organisation to innovate [26,27]. The innovation capability model, as developed by Essmann [8], includes three innovation capability areas: innovation process, knowledge and competency, and organisational support, as well as 10 detailed innovation capability requirements [8].

\subsubsection{Relationship between external innovation domain components}

Relationships exist between the three components within the external innovation domain or innovation strategy domain. 
Governance - Scope: The innovation scope is largely determined by the innovation governance framework. The answers to why innovate, where, and how much innovation, are determined within the governance framework. These answers inform the decisions on innovation type, level, and impact that form part of the innovation scope.

Governance - Capability: One of the key questions in the innovation governance framework is how a company can innovate more effectively. By linking this question to the innovation capability maturity model and the company's innovation maturity in the various capability requirements, it is possible to identify weaknesses in the company's innovation capability, which can then be improved through a formal innovation capability improvement process. From the other direction, the current innovation capability may dictate how several of the innovation governance questions are answered.

Scope - Capability: The innovation scope guides a company in determining the appropriate innovation capability maturity level. Where the innovation scope includes significant radical and disruptive innovation, the innovation capability maturity of a company may need to be higher than if the company were focusing on incremental innovation. The scope also helps a company to target its innovation capability improvement efforts by highlighting certain key capabilities that are required to excel in specific types of innovation with specific desired impacts. The relationship between these two components can also work the other way: the innovation scope can be limited by the company's innovation capability. The scope can change over time as the company's innovation capability matures.

\subsection{Internal domain components of iSAM}

The internal domain focuses on a company's internal innovation infrastructure and processes. Within the internal domain of both the business strategy and the IT strategy in the SAM, three components are described that represent three sets of choices managers need to address. We postulate that three similar sets of choices are required by managers in relation to internal innovation infrastructure and processes.

\subsubsection{Innovation model and processes}

The choices for this component involve which innovation model to apply and, subsequently, which are the most appropriate innovation processes to implement. The innovation literature describes a number of different innovation model categories. These catagories are based on the approach to innovation [28], or on the progress of innovation maturity [29], or on different leadership styles [30]. This is analogous to the internal business administrative structures, which define the roles, responsibilities, and authority structures, and to the design of the internal business processes required (for the company) to execute its business strategies.

Rothwell's classification of innovation models defines five generations of innovation model, ranging from linear models that involve market pull and technology push to the fifth-generation models that address systems integration and extensive networking, flexible and customised response, and continuous innovation [29]. IBM has defined four different innovation archetypes [28]: the marketplace of ideas, the visionary leader, systematic innovation, and external collaborative innovation. The innovation leadership models provide a company with a range of options for leading innovation. Nine different innovation leadership models have been suggested, ranging from the 'CEO model' to the 'no-one in charge' model [30].

\subsubsection{Innovation systems}

The choices for this component of an innovation system depend heavily on the choice of innovation model and the subsequent innovation processes.

\subsubsection{Innovation skills}

The choices for this component relate to the identification, acquisition, and development of the necessary skills to drive successful innovation. This is analogous to the skills required within the business domain to implement a specific strategy successfully. Innovation skills can be classified into two broad categories: skills required for innovation specific positions, and innovation-relevant skills required by non-specific innovation positions. For innovation specific positions - as with all positions - job profiles, competency frameworks, and performance management components need to be developed. For non-innovation specific positions, innovation components should be built into the job profile. Innovation skills should also form part of a company's skills development and skills acquisition plan. 


\subsubsection{Relationship between internal innovation domain components}

Relationships exist between the three components within the internal innovation domain or innovation infrastructure and process domain.

Models and processes - System: The choice of a specific innovation system in a company is influenced by the preferred innovation model and subsequent processes. The innovation system is designed and implemented to support the preferred innovation model. A system to support a bottom-up 'marketplace of ideas' model will be very different from a system designed to support a top-down 'visionary leadership' model.

Models and processes - Skills: The selection of a preferred innovation model influences the innovation skills required in a company. Different innovation models require different skills at all levels in a company. The current skill levels should also be considered when selecting a preferred innovation model. Based on the current skill set, certain innovation models should be avoided until the necessary skills have been developed or acquired.

Systems - Skills: The innovation skills should be taken into consideration when designing or acquiring a specific innovation system. Companies with a low innovation maturity may require either a simpler system or one that automates more of the innovation process.

\subsection{The comprehensive iSAM model}

The comprehensive iSAM model is presented in Figure 1.

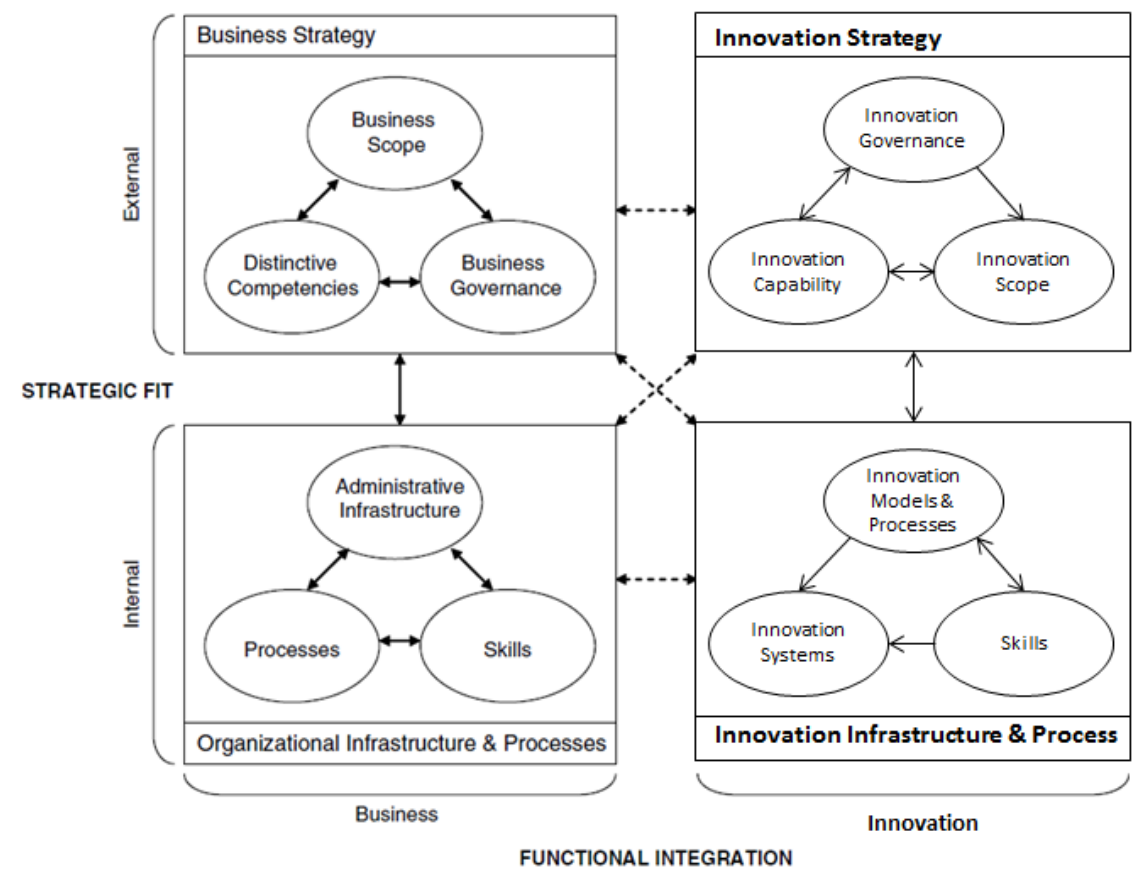

Figure 1: iSAM with all components and relationships

\subsection{Alignment in ISAM}

There are three types of alignment in iSAM. Strategic fit is the alignment between the external strategy domains and the internal infrastructure and process domains. This alignment is critical, as there is no benefit in having a well-developed strategy if the infrastructure and processes that are needed to deliver the strategy are either insufficient or inappropriate. In a review of various research attempts to measure fit, Avison et al. [5] report that there is little consensus between the leading authors about the factors involved in measuring fit. Functional integration deals with the alignment between the business and a functional area such as HR, IT, or innovation. In iSAM, the functional strategic integration deals with the strategic alignment between the innovation strategy and the business strategy. The functional infrastructure and process integration is defined by the link between the innovation infrastructure and processes and the business infrastructure 
and processes. The third type of alignment is termed 'cross-domain alignment', and addresses the issue of where change is initiated in a company, and the order of that change.

\subsubsection{Innovation alignment perspectives}

Three alignment perspectives are defined in iSAM: the business strategy perspective, the innovation transformation perspective, and the innovation potential perspective. These alignment perspectives describe the way in which a company adapts to changes, in its internal and external environments, in order to regain alignment after such a change. A company should select one alignment perspective that best suits its philosophy to change. The other alignment perspectives may also be relevant under certain circumstances, but the main alignment perspective of a company should always be the most dominant. Each alignment perspective has one dominant domain that is the driving force, and usually the initiator, of change. This domain often has the strongest representation at the executive level in the company, and is often referred to as the 'anchor' domain. Coleman et al. [6] consider the anchor domain to be the quadrant that is the strongest area of the business. It directs the change that the business is to undergo.

In the business strategy perspective, the business strategy is the main driver or anchor domain. In this perspective, people or other resources are unlikely to be dedicated directly to innovation. Therefore, from an external innovation domain perspective, the scope of innovation would be limited (focusing on incremental improvements), the innovation governance activities would be minor, and the innovation capability level of the company would be low, without much on-going effort to improve it. From an internal innovation domain perspective, the innovation model would not rely heavily on an innovation team. The innovation leadership would come from alreadyestablished management teams or individuals. The types of companies that would best fit the business strategy perspective are those with a strong operational focus that have to do the same activities repeatedly. These companies gain competitive advantage through operational efficiencies, and have significant capital invested in operational infrastructure.

The innovation transformation perspective places the innovation strategy at the center of implementing the chosen business strategy, which is the anchor domain. In this perspective, a company has made a decision that the innovation activities should not be constrained by the current business infrastructure and processes. Instead, the innovation strategy - made up of the scope, governance, and capability - should be aligned with the overall business strategy. The correct innovation infrastructure - including model, processes, and skills - should then be designed and implemented to support the implementation of the innovation strategy. For example, a company with a first-to-market generic strategic perspective (business strategy) should have an innovation strategy that focuses on radical and disruptive innovation (scope), which in turn would require a mature innovation capability and governance structures. To implement this innovation strategy successfully, it would need to select an innovation model geared for this level of innovation, and would need to support this model through appropriate innovation processes and skills. The types of companies that would best fit the innovation transformation perspective are those that gain competitive advantage through their ability to adapt and change to shifts in the external environment. Innovation is not at the core of these companies, but they have the ability to innovate in order to implement successful change and significantly improve their core business.

In the innovation potential perspective, a company designs a new business strategy for the potential competitive advantage its innovation strategy could provide. The business infrastructure and processes are then developed to implement the new business strategy. In this perspective, a company realises that the broad scope of innovations it is able to deliver - together with its significant innovation capability and innovation governance structures - places it in a position to make changes to its business strategy so that it can better exploit its innovation capability. If this new business strategy is supported by a changed and aligned business infrastructure and processes, then a significant competitive advantage may be gained. This approach requires strong innovation leadership, and will more than likely be driven by the CEO or senior management team and employ a 'visionary leader' innovation model. The types of companies that would best fit the innovation potential perspective are those whose business is innovation. These companies are found in fastchanging industries with high levels of uncertainty about the future, and where innovation has the capability to disrupt the entire structure and pecking order. Innovation is not being applied to improve other core competencies such as low cost or improved quality: innovation is the core competency, and these companies gain a competitive advantage from being able to innovate better and faster than their competitors. 


\subsubsection{Deciding on an apropriate alignment perspective for a specific company}

Two main factors need to be considered when deciding on the appropriate alignment perspective for a specific company. Other factors play a role, such as the innovation model, the industry in which the company operates, and the balance of influence within the executive committee. However, these are all influenced by the two main factors: the company's grand strategy, and the company's innovation strategy. A company with a first-to-market grand strategy is more likely to adopt an innovation transforming or innovation potential alignment perspective, while a company looking to gain competitive advantage through cost reduction may opt for the business strategy alignment perspective. A company with a strong focus on radical and disruptive strategic or product innovation, as well as a company with a high level of innovation maturity, is best suited for either an innovation transforming or innovation potential alignment perspective. A company with a focus on more incremental innovation may be best suited for the business strategy alignment perspective.

\section{AN APPROACH TO ASSESSING THE CURRENT STATE OF OF A COMPANY'S ALIGNMENT}

In this section, an innovation strategy alignment approach, using the iSAM, is presented to assess the current state of alignment between a company's internal and external business and innovation domains. This approach uses the concepts of strategic fit, functional alignment, and alignment perspectives (cross-domain alignment) to work methodically through the alignment between a company's business and innovation components. Strategy, like innovation, is very much about change. A company decides on a strategy and then spends time and effort in implementing that strategy. In the process, internal skills, processes, and infrastructure may need to be changed to align with the new strategy. This is just as applicable to the innovation strategy as it is to the overall business strategy. In executing the strategy, the company may develop new products, enter new markets, develop new innovation capabilities, implement a new innovation model, or do other things to achieve its strategic objectives. Furthermore, projects in companies today are the vehicle by which change occurs both internally or externally. Projects only exist if a change is required. The suggested innovation strategy alignment approach is presented in Figure 2.

If it is found that a company is currently well-aligned, then an analysis of its current and planned projects will help to determine whether the alignment will be maintained ( $4 \mathrm{~b}$ in Figure 2 ). If, however, the company is not aligned, then the appropriate alignment perspective should be followed to determine whether the current and planned projects will achieve alignment, or whether some projects should be stopped and others initiated (5a, b, c in Figure 2).

Six different project types have been defined, based on the domains in the iSAM:

- Project type 1 (P1): External non-innovation projects - these drive the achievement of the external business strategy

- $\quad$ Project type $2(\mathbf{P 2})$ : Internal non-innovation projects - these drive the achievement of the internal business infrastructure and processes

- Project type 3 (P3): External innovation projects - these drive the achievement of the business strategy and need to be aligned with the innovation strategy

- $\quad$ Project type 4 (P4): Internal innovation projects - these drive the achievement of the business infrastructure and processes and need to be aligned with the innovation strategy

- $\quad$ Project type 5 (P5): Internal innovation process projects - these drive the achievement of the internal innovation infrastructure and processes

- $\quad$ Project type 6 (P6): External innovation projects not aligned to business strategy -these do not assist in achieving the current business strategy, but may lead to a new business strategy in the future

\subsection{Application of approach (case study)}

In order to demonstrate the approach to determining a company's current state of innovation alignment, the approach has been applied to the South African division of a mid-size consulting company. The company provides consulting services and technical assistance to government departments to strengthen their service delivery systems. These systems range from strategic planning and decision-making to day-to-day operational activities. These projects are usually notfor-profit projects, paid for by international funding organisations. The company also provides consulting services to other companies looking to sell products and services to government departments in African countries. These projects are usually for profit, paid for by the client. 


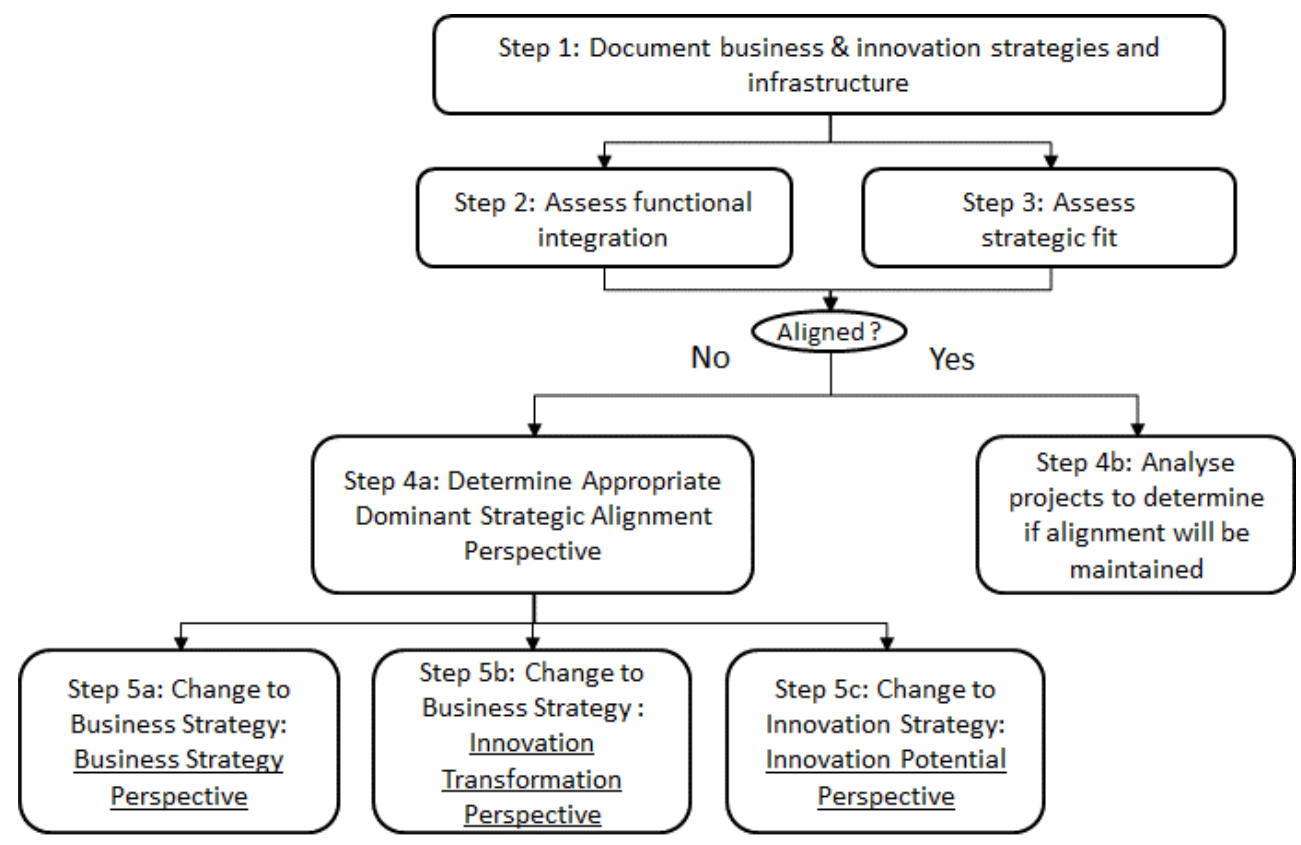

Figure 2: Approach to assessing a company's current state of alignment

\subsubsection{Step 1: Document the current business and innovation domains}

In step one, each of the three components in each of the four domains in iSAM is described for the company. This is achieved through analysis of strategic and operational documents and discussions with the company's management. The following list is a subset of the full analysis, and presents the key outputs for this step of the approach.

1. Main target market: Government departments in developing countries

2. Main products: Consulting services and technical assistance

3. Key business principles: Social entrepreneurship, data-driven, scalable and sustainable solutions, blend private and public sector approaches

4. Distinctive competencies: Global network and reach, local understanding of how government services are delivered on the ground, able to operate in both the public and the private sectors

5. Primary generic strategy: First-to-market generic strategy, attempting to be seen as leaders in their field by being the first to introduce a solution or to follow a novel approach

6. Innovation scope: Type - Strong product, medium strategy, weak process. Level - Medium radical, medium incremental. Impact - Medium sustaining, medium disrupting

7. Innovation governance structures: No formal innovation governance forums or structures exist in the company

8. Innovation capability maturity level: Unaware of innovation. Although innovation is communicated as an important part of the competitive advantage and culture of the company, there is no formalisation of innovation, to the point where the understanding of the term 'innovation' is not always clear

9. High-level structure: Standard hierarchical structure that is three to four layers deep

10. Competency framework: A competency framework consisting of five dimensions and 40 relevant competencies is used in the company

11. Innovation model: Visionary leadership

12. Innovation processes: No formal innovation processes exist in the company

13. Innovation competencies: There are several innovation-related competencies in the overall company competency framework

14. Innovation roles: There are no innovation-specific roles in the company

15. Innovation competency improvement activities: There are no innovation-specific innovation competency improvement activities 


\subsubsection{Step 2: Assess functional integration}

The innovation strategy alignment framework developed by Katz et al. [31] is presented in Table 1. The relationship between the competitiveness strategy and the innovation scope is defined as weak, medium, or strong [32]. The other components in the innovation strategy domain in iSAM innovation governance and innovation capability - either influence, or are influenced by, the innovation scope. Therefore, if the innovation scope is aligned with the grand strategy, these other two components should also be aligned.

Table 1: Relationships between innovation components and competitive strategies [32]

\begin{tabular}{|c|c|c|c|c|c|}
\hline \multirow{2}{*}{\multicolumn{2}{|c|}{$\begin{array}{c}\text { Components of an } \\
\text { Innovation Strategy }\end{array}$}} & \multicolumn{4}{|c|}{ Porter's Four Generic CompetitiveStrategies } \\
\hline & & $\begin{array}{c}\text { Overall cost } \\
\text { leadership } \\
\text { (Cost Reducer) }\end{array}$ & $\begin{array}{c}\text { Overall } \\
\text { differentiation } \\
\text { (First to market) }\end{array}$ & $\begin{array}{c}\text { Focus-segment } \\
\text { cost leadership } \\
\text { (Cost } \\
\text { Reducer/Niche) }\end{array}$ & $\begin{array}{l}\text { Focus-segment } \\
\text { differentiation } \\
\text { (Niche) }\end{array}$ \\
\hline \multirow{3}{*}{$\begin{array}{c}\text { Innovation } \\
\text { Type }\end{array}$} & Product & Medium & Medium & Strong & Strong \\
\hline & Strategic & Weak & Strong & Medium & Strong \\
\hline & Process & Strong & Weak & Medium & Weak \\
\hline \multirow{2}{*}{$\begin{array}{c}\text { Innovation } \\
\text { Level }\end{array}$} & Radical & Weak & Strong & Medium & Medium \\
\hline & Incremental & Strong & Medium & Strong & Medium \\
\hline \multirow{2}{*}{$\begin{array}{l}\text { Innovation } \\
\text { Impact }\end{array}$} & Sustaining & Strong & Weak & Medium & Medium \\
\hline & Disruptive & Weak & Strong & Medium & Strong \\
\hline
\end{tabular}

This strategic alignment framework [31] presented in Table 1 is used to assess the company's functional strategic integration. The first step is to understand its preferred generic competitiveness strategy or grand strategy. Based on the analysis in step one, the company strives to achieve a first-to-market strategy. Based on the strategic alignment framework [31] in Table 1, this strategy would suggest that the preferred innovation type, level, and impact should be strategic, radical, and disruptive innovation, with less focus on incremental product innovation and a low focus on sustaining process innovation. The company seems to have a stronger focus on product innovation and less focus on strategic innovations, as well as an equal focus on radical and incremental innovation and on sustaining and disruptive innovation. As the company does not have an explicit and formal innovation strategy, the past innovation focus or pattern of innovations assists in defining an implicit strategy [33]. While the implicit innovation strategy is not too far off the ideal situation for a first-to-market company, it still reveals a misalignment between the company's grand strategy and its innovation strategy. It is difficult to determine the level of alignment, as there are few formal innovation infrastructures or processes in the company.

\subsubsection{Step 3: Assess strategic fit}

From an innovation perspective, there is no strategic fit in the company. It does not have a formal innovation strategy; but even if the implicit innovation strategy is taken into consideration, there is no formal innovation infrastructure or process.

\subsubsection{Step 4a: Determine appropriate dominant strategic alignment perspective}

Based on the analysis of the functional integration and strategic fit, there does seem to be a level of misalignment in the company. Therefore $4 \mathrm{a}$ is the next step in the analysis. Taking the two main factors of the grand strategy and the innovation strategy into account, the fact that the company pursues a first-to-market grand strategy and has some radical, disruptive innovation in its implicit innovation strategy points to either the innovation transformation or the innovation potential alignment perspectives being the most appropriate perspective for this company. The company's first-to-market grand strategy clearly reveals that it aims to gain competitive advantage through innovation. The company's current implicit innovation strategy is slightly less radical and disruptive than is required from a first-to-market company, but that is the reason for the identified misalignment in the functional strategic integration. The lack of a formal innovation strategy or any formal innovation infrastructure or processes would indicate that while innovation is important to the company, the business strategy is still the main driver of change. Therefore the innovation transformation perspective would appear to be the most appropriate dominant perspective. This perspective will guide the steps through the alignment pathway in step five of the approach. 


\subsubsection{Step 5c: Innovation transformation alignment perspective}

The pathway to alignment, based on the innovation transformation alignment perspective, is presented in Figure 3. This alignment pathway involves 11 steps, in which the required changes to the four iSAM domains are identified and the current and planned projects are analysed to check their alignment with the four domains. For the company in the case study, 43 current and planned projects were analysed. In the innovation transformation alignment perspective the change is initiated in the business strategy - step one in Figure 3. Once the business strategy has changed, it is important to check the external projects (P1) to ensure that they are still aligned with the new business strategy. Functional integration between the business strategy and the innovation strategy is then checked, and the innovation strategy is adjusted to realign it with the new business strategy. Once the new innovation strategy is defined, the external innovation projects (P3 \& P6) are checked to ensure that they are still aligned. The strategic fit between the new business strategy and business infrastructure and processes is checked, and the projects impacting the infrastructure and processes (P2 \& P4) are adjusted to ensure alignment. Finally, the strategic fit between the adjusted innovation strategy and innovation infrastructure and processes is checked, and the projects (P5) impacting the innovation infrastructure and processes are adjusted to ensure re-alignment.

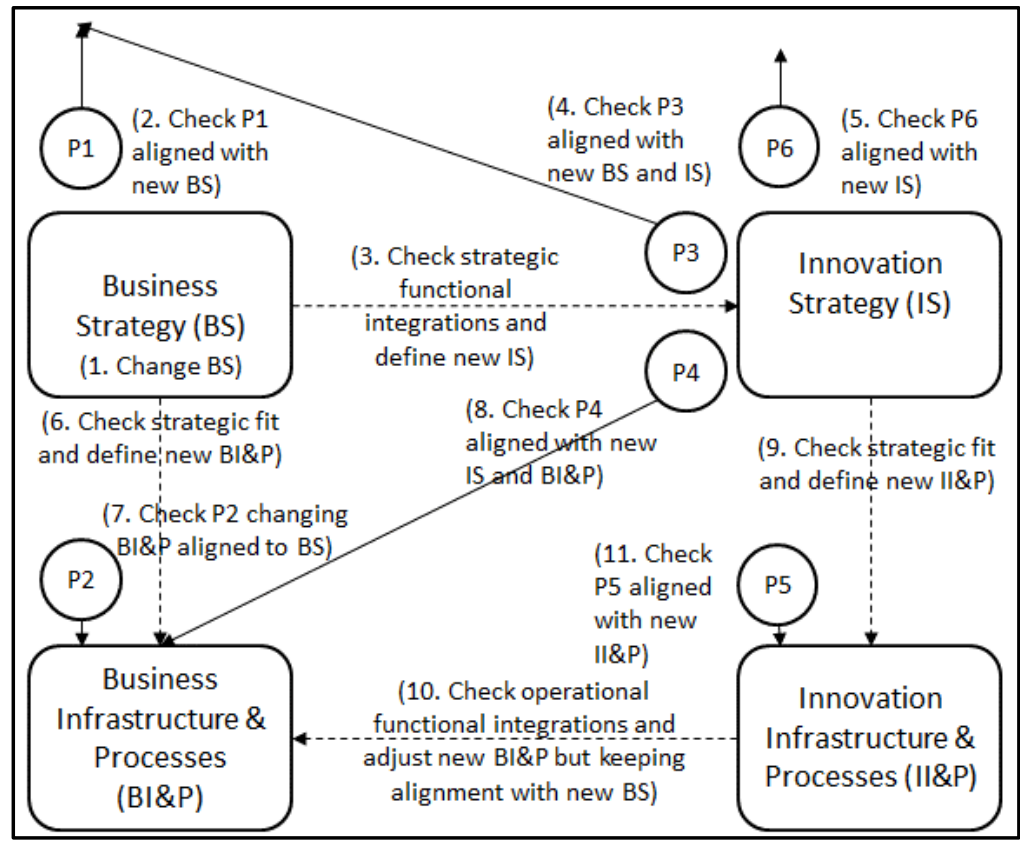

Figure 3: Path to alignment based on the innovation potential alignment perspective

The breakdown of the 43 projects by project type is presented in Table 2 .

Table 2: Breakdown of 43 projects by project type

\begin{tabular}{clc}
\hline & \multicolumn{1}{c}{ Project Type } & $\begin{array}{c}\text { Number of } \\
\text { Projects }\end{array}$ \\
\hline P1 & External non-innovation project & 17 \\
P2 & Internal non-innovation project & 21 \\
P3 & $\begin{array}{l}\text { External innovation project aligned } \\
\text { with business strategy }\end{array}$ & 3 \\
P4 & Internal innovation project & 0 \\
P5 & Internal innovation processes project & 0 \\
& External innovation project not & 1 \\
P6 & aligned to business strategy & \\
\hline
\end{tabular}




\subsubsection{Results of analysis}

The results of the analysis of the company in question revealed areas of both good and poor alignment. The business strategy is well-defined, and the majority of projects are aimed at achieving either the business strategy or the business infrastructure and processes required to achieve the business strategy. The few truly innovative projects that exist also seem to align well with the business strategy. No formal innovation strategy exists. However, the implicit innovation strategy is slightly misaligned with the business strategy, and should have a stronger focus on strategic, radical innovation truly to align with the company's first-to-market grand strategy. The area of poor alignment in the company is in the innovation infrastructure and processes domain. There are no formal innovation infrastructure and processes, and there are no current or planned projects aimed at rectifying the situation. The implication of this shortcoming is that innovations will be successful through a combination of chance and the significant efforts of specific individuals. This, in turn, limits the company's ability truly to achieve a first-to-market grand strategy in a consistent way. The results of the innovation transformation perspective analysis, and recommendations, are presented in Table 3.

\section{CONCLUSIONS}

Competitiveness and company performance requires the alignment of short-, medium- and longterm internal and external activities in an ever-changing environment. The ability to innovate can give companies significant competitive advantage - but only if the rest of the company can align with the change brought about by the innovation. A framework to align, deploy, and consolidate improvement projects becomes increasingly vital. This research provides two key contributions:

- $\quad$ The development of the iSAM based on the IT-specific SAM

- The development of an approach to assessing the current state of alignment between a company's internal and external business and innovation domains

In the development of the iSAM, six detailed innovation components - three per innovation domain - are proposed. Next, three different types of alignment (strategic fit, functional integration, and cross-domain alignment) are documented. Based on the relationships between the different innovation components and the required alignment between the innovation and business domains, three innovation alignment perspectives are then defined.

Using a five-step process, the alignment of a mid-size consulting company was assessed. The results of this assessment reveal that:

- There is a slight misalignment between the grand strategy and the implicit innovation strategy;

- There is a lack of a formal innovation strategy and formal innovation infrastructure and processes;

- The most appropriate innovation alignment perspective for this company is the innovation transformation alignment perspective;

- Current and planned projects are aligned with the business strategy, but there are no projects focusing on the development of formal innovation infrastructure and processes; and

- While there is one project focusing on innovation beyond the current business strategy, this number would seem low for a company striving to gain competitive advantage by being firstto-market.

Overall, the company's innovation activities are not fully aligned with its business activities, and the set of current and planned projects will not ensure full alignment in the future and should be reviewed. The model and approach that was developed seem to have merit in that they encompass the majority of the key innovation components required in a company, and provide an overarching framework to align the business and innovation domains. The application of the approach followed a logical, step-wise method, and it would seem to be replicable for other companies. Further case studies are required to test fully the robustness of the model, and the approach and mechanism to measure the impact of the recommendations is required truly to understand the full benefits of the model. 
Table 3: Summary of analysis results and recommendations

\begin{tabular}{|c|c|c|c|}
\hline & Analysis Step & Analysis & Recommendations \\
\hline 1 & Change BS (if required) & The $B S$ is well defined & $\begin{array}{l}\text { There are no internal or external reasons for } \\
\text { BS to change at the moment }\end{array}$ \\
\hline 2 & $\begin{array}{l}\text { Check external non- } \\
\text { innovation projects (P1) are } \\
\text { aligned with BS }\end{array}$ & $17 / 17$ P1 type projects, all aligned with BS & No need to stop or adjust any $\mathrm{P} 1$ type projects \\
\hline 3 & $\begin{array}{l}\text { Check strategic functional } \\
\text { integration and define new } \\
\text { IS }\end{array}$ & $\begin{array}{l}\text { Explicit IS does not exist \& the implicit IS } \\
\text { has too high a focus on incremental, } \\
\text { product innovation to be aligned with BS }\end{array}$ & $\begin{array}{l}\text { Answer the innovation governance questions } \\
\text { and document explicit IS with greater focus } \\
\text { on radical, product \& strategicinnovations }\end{array}$ \\
\hline 4 & $\begin{array}{l}\text { Check external innovation } \\
\text { project aligned with } \\
\text { business strategy (P3) } \\
\text { projects aligned with BS and } \\
\text { IS }\end{array}$ & $\begin{array}{l}\text { 3/3 P3 type projects, all aligned with BS } \\
\text { and updated IS }\end{array}$ & No need to stop or adjust any P3 type projects \\
\hline 5 & $\begin{array}{l}\text { Check external innovation } \\
\text { projects not aligned to } \\
\text { business strategy (P6) are } \\
\text { aligned with new IS }\end{array}$ & $\begin{array}{l}\text { 1/1 P6 type projects aligned with updated } \\
\text { IS }\end{array}$ & $\begin{array}{l}\text { No need to stop or adjust P1 type project } \\
\text { although with a stronger focus on radical and } \\
\text { disruptive innovation, more P6 type projects } \\
\text { may be required }\end{array}$ \\
\hline 6 & $\begin{array}{l}\text { Check strategic fit and } \\
\text { define new BI\&P }\end{array}$ & $\begin{array}{l}\text { No analysis was conducted on the strategic } \\
\text { fit between the business domains as this is } \\
\text { not directly related to the innovation } \\
\text { domains }\end{array}$ & None \\
\hline 7 & $\begin{array}{l}\text { Check Internal non- } \\
\text { innovation projects (P2) } \\
\text { changing BI\&P aligned to BS }\end{array}$ & $\begin{array}{l}\text { 21/21 P2 type projects, all changing BI\&P } \\
\text { aligned to BS }\end{array}$ & No need to stop or adjust any P2 type projects \\
\hline 8 & $\begin{array}{l}\text { Check internal innovation } \\
\text { projects (P4) aligned with IS } \\
\text { and changing BI\&P aligned to } \\
\text { BS }\end{array}$ & $\begin{array}{l}\text { There are no P4 type projects currently } \\
\text { being executed or planned }\end{array}$ & $\begin{array}{l}\text { Company should investigate how the } \\
\text { innovation processes could play a significant } \\
\text { role in any internal improvement or change }\end{array}$ \\
\hline 9 & $\begin{array}{l}\text { Check strategic fit and } \\
\text { define new II\&P }\end{array}$ & $\begin{array}{l}\text { No formal innovation in frastructure or } \\
\text { processes exist. }\end{array}$ & $\begin{array}{l}\text { Formal innovation infrastructure and } \\
\text { processes should be implemented inline with } \\
\text { new IS }\end{array}$ \\
\hline 10 & $\begin{array}{l}\text { Check operational functional } \\
\text { integrations and adjust BI\&P } \\
\text { but keeping alignment with } \\
\text { new BS }\end{array}$ & $\begin{array}{l}\text { No formal innovation infrastructure or } \\
\text { processes exist, therefore operational } \\
\text { functional in tegration between BI\&P and } \\
\text { IIAP cannot be checked }\end{array}$ & $\begin{array}{l}\text { Implement formal innovation infrastructure } \\
\text { and processes and adjust BI\&P accordingly, } \\
\text { keeping alignment with BS }\end{array}$ \\
\hline 11 & $\begin{array}{l}\text { Check internal innovation } \\
\text { processes projects (P5) } \\
\text { aligned with II\&P }\end{array}$ & $\begin{array}{l}\text { There are no P5 type projects and no formal } \\
\text { innovation infrastructure or processes exist. }\end{array}$ & $\begin{array}{l}\text { Once formal innovation infrastructure or } \\
\text { processes are defined a number of P5 type } \\
\text { projects should be developed in order to } \\
\text { implemented the II\&P }\end{array}$ \\
\hline
\end{tabular}

\section{REFERENCES}

[1] Reeves, M. \& Deimler, M. 2011. Adaptability: The new competitive advantage, Harvard Business Review, 89 (7/8), pp 134-141.

[2] Kaplan, R.S. \& Norton, D.P. 2006. Alignment: Using the balanced scorecard to create corporate synergies, Harvard Business School Press.

[3] Hough, J., Strickland, A.J., Gamble, J.E. \& Thompson, A.A. 2008. Crafting and executing strategy, South African edition, McGraw-Hill.

[4] Henderson, J.C. \& Venkatraman, N. 1993. Strategic alignment: Leveraging information technology for transforming organizations, IBM Systems Journal, 32(1), pp 472-484.

[5] Avisona, D., Jones, J., Powell, P. \& Wilson, D. 2004. Using and validating the strategic alignment model, Journal of Strategic Information Systems, 13, pp 223-246.

[6] Coleman, P. \& Papp, R. 2006. Strategic alignment: Analysis of perspectives, Proceedings of the Southern Association for Information Systems Conference, pp 242-250.

[7] Samuel, P. 2009. Everybody is responsible for innovation, interview on onesixsigma.com, February 2015.

[8] Essmann, H.E. 2009. Toward innovation capability maturity, PhD Thesis, Stellenbosch University.

[9] TheFreeDictionary.com 2014. http://www.thefreedictionary.com/alignment, November 2014.

[10] Hiekkanen, K., Helenius, M., Korhonen, J.J. \& Patricio, E. 2013. Aligning alignment with strategic context: A literature review, Digital Enterprise Design and Management, 205, pp 81-98.

[11] Lear, L.W. 2012. The relationship between strategic leadership and strategic alignment in highperforming companies in South Africa, PhD Thesis, University of South Africa.

[12] Kaplan, R.S \& Norton, D.P. 2001. Transforming the balanced scorecard from performance measurement to strategic management: Part II, Accounting Horizons, 15(2), pp 147-160.

[13] Kaplan, R.S. \& Norton, D.P. 2006. Alignment: Using the balanced scorecard to create corporate synergies, Boston: Harvard Business School Press. 
[14] Luftman, J. 2000. Assessing business-IT alignment maturity, Communications for the associations of information systems, 4(14), pp 1-50.

[15] Dobni, C.B. 2010. Achieving synergy between strategy and innovation: The key to value creation, International Journal of Business Science and Applied Management, 5(1), pp 48-58.

[16] Duppen, F. \& Inniss, D. 2010. CapGemini: Innovation Leadership Study, CapGemini Consulting.

[17] Jaruzelski, B., Loehr, J. \& Holman, R. 2011. Why culture is key, Booz \& Company's Global innovation 1000 study, Booz \& Company Inc.

[18] Deschamps, J.P. 2012. What is innovation governance?, www.imd.org, November 2014.

[19] Teece, D.J., Pisano, G. \& Shuan, A. 1997. Dynamic capabilities and strategic management, Strategic Management Journal, 18(7), pp 509-33.

[20] Damenpour, F. 1991. Organizational innovation: A meta-analysis of effects of determinants and moderators, Academy of Management Journal, 34(3), p 555-590.

[21] Taylor, J.E. 2005. Three perspectives on innovation in interorganizational networks, PhD Thesis, Stanford University.

[22] Asgarian, N. 2012. Knowledge management capacity and innovation performance, Management Science Letters, 2, pp 2739-2746.

[23] Williams, C. \& Choi, S.B. 2012. Impact of innovation intensity, scope and spill-overs on sales growth of Chinese firms, Asia Pacific Journal of Management, 31(1), pp 25-46.

[24] Richardson, A. 2010. Innovation X: Why a company's toughest problems are its greatest advantage, Adam Jossey-Bass.

[25] Katz, B.R., du Preez, N.D. \& Schutte, C.S.L. 2010. Definition and role of an innovation strategy, SAllE conference proceedings, pp 60-74.

[26] Neely, A., Filippini, R., Forza, C., Vinelli, A. \& Hii. J. 2001. A framework for analysing business performance, firm innovation and related contextual factors: Perceptions of managers and policy makers in two European regions, Integrated Manufacturing Systems, 12(2), pp 114-124.

[27] O'Connor, G.C. \& Ayers, A.D. 2005. Building a radical innovation competency, Research-Technology Management, Jan-Feb, pp 22-31.

[28] IBM Innovation Archetypes. 2011. www.-03IBM.com/ innovation/ discovery/ archetypes, October 2014.

[29] Entekhabi, M. \& Abbas Arabshahi, G.H. 2012. Classification of innovation projects, Indian Journal of Innovations Development, 1(8), pp 612-625.

[30] Deschamps, J.P. 2012. The nine models of innovation governance, www.imd.org, November 2014.

[31] Katz, B.R., Du Preez, N.D. \& Schutte, C.S.L. 2011. Alignment of a functional innovation strategy, Proceedings ISEM Conference, https://www.saiie.co.za/cms/content/567-ISEM-2011, February 2014.

[32] Katz, B.R., Du Preez, N.D. \& Schutte, C.S.L. 2013. The relationship between an innovation strategy and a technology strategy, Proceedings of Competitiveness in Manufacturing (COMA) Conference, pp 461 468.

[33] Mintzberg, H. 1987. The strategy concept I: 5 P's for strategy, California Management Review, Fall, pp 11-24. 